\title{
REINFORCEMENT AND REPRODUCTIVE CHARACTER DISPLACEMENT IN GASTROPHRYNE CAROLINENSIS AND G. OLIVACEA (ANURA: MICROHYLIDAE): A REEXAMINATION
}

\author{
JASPER J. LOFTUS-HILLs' \\ Museum of Zoology, University of Michigan, Ann Arbor, Michigan, 48109 USA \\ AND \\ MurRay J. LitTLEJohN \\ Department of Zoology, University of Melbourne, Parkville, Victoria 3052, AUSTRALIA
}

\begin{abstract}
Tape-recorded advertisement calls of Gastrophryne carolinensis and G. olivacea, obtained in Texas and southern Louisiana, were analyzed by means of an analogue audiospectrograph. Samples were grouped into four areas: allopatric and sympatric for $G$. carolinensis, and combined adjacent allopatric/shallow sympatric, and sympatric for $G$. olivacea. Three attributes of the advertisement call (call duration, pulse rate, and dominant frequency) were investigated, with water temperature at the calling site as the independent variable. Values for dominant frequency do not overlap between species, across the full range of recording temperatures, and those of sympatric $G$. carolinensis are displaced away from those of both groups of $G$. olivacea (which are very similar)thus indicating a pattern of geographic variation consistent with reproductive character displacement. There is considerable overlap in the values for duration and for pulse rate of each species when considered alone, but there is only slight overlap of the scatters of points for the pairs of values. For both species, no consistent patterns of correlation were detected between the three attributes of the call and the snout-vent length of the emitter, thus reducing the likelihood that the divergence in calls is due to pleiotropic effects of body size.
\end{abstract}

Key words. - Advertisement calls, acoustic communication, geographic variation, pleiotropic effects, speciation, sympatric interactions.

Received April 9, 1991. Accepted January 7, 1992.

The two species of narrow-mouthed toads, Gastrophryne carolinensis (Holbrook) and G. olivacea (Hallowell), are widely distributed in the central and southern United States, with the mesic-adapted species, $G$. carolinensis, occurring in the southeast, and xeric-adapted species, $G$. olivacea, in the southwest (Nelson, 1972a, 1972b, 1972c). There is a zone of sympatry with a width (east-west) of about $400 \mathrm{~km}$, and a length (north-south) of about $1,100 \mathrm{~km}$ (based on maps presented by Nelson, 1972b, 1972c) in eastern Texas and eastern Oklahoma. However, detailed surveys of geographic limits to distribution are lacking; and given the records of possible outliers of $G$. carolinensis at two localities in Texas (Kerrville and Brownsville, Nelson, 1972b), these maps should be treated as only providing a general picture of the geographic ranges.

Blair (1955a) presented the first quantitative study of geographic variation in an

'Deceased, 11 June 1974. acoustic attribute of an animal species, namely the comparison of tape-recorded advertisement calls (referred to as mating calls) of males of $G$. carolinensis and $G$. olivacea in allopatric and sympatric populations. This extensive geographical study included samples of calls from localities as far apart as Arizona ( $G$. olivacea) and northern Florida ( $G$. carolinensis), a distance of more than $2,500 \mathrm{~km}$. He studied two attributes of the advertisement calls: call duration, and the midpoint of the emphasized band of frequencies. A comparison of the grouped samples (Blair, 1955a; Fig. 4) indicated that interspecific differences in midpoint frequency were greatest in those from sympatry, particularly in $G$. olivacea, but ranges of variation overlapped. Interspecific differentiation in call duration was less-marked than in midpoint frequency. As the zone of geographic overlap is now known to be much wider than was assumed by Blair (1955a), all of his samples of $G$. carolinensis from "east of overlap" and most of those of $G$. olivacea from "west of overlap" are prob- 
ably from sympatry. (Compare the maps of Nelson, $1972 b, 1972 c$ with Fig. 1 of Blair, 1955a.)

Hybridization has been reported between these two species, based on individuals of intermediate morphology and call structure (reviewed by Nelson, 1972a); but the fertility of the putative hybrids has not been determined (Blair, 1955a). Furthermore, laboratory evidence for viability and fertility of artificially produced hybrids is inconclusive (Blair, 1955a). Eight apparent hybrids in a sample of 100 individuals recorded in his zone of sympatry were identified by Blair (1955a), on the basis of values for both attributes of the call falling between those of the sympatric samples, although somewhat closer to those of $G$. carolinensis. Blair (1955a; p. 479) commented that: "The argument for reinforcement of isolation mechanisms through selection against hybridization is premised on the hybrids being at a disadvantage in competition with the parental types." It is clear from this quotation that Blair (1955a) was applying the term "reinforcement" to a process (as a subset of natural selection) that operates to reduce the likelihood of mistakes in mate choice that result in lowered reproductive success. That is to say, reinforcement leads to the evolution of more efficient systems of homogamy (Littlejohn, 1981, 1988).

Brown and Wilson (1956; p. 63) defined character displacement as: "... the situation in which, when two species of animals overlap geographically, the differences between them are accentuated in the zone of sympatry and weakened or lost entirely in the parts of their ranges outside this zone." Furthermore, they noted that: "Upon meeting, the two populations interact through genetic reinforcement of species barriers and/or ecological displacement in such a way as to diverge further from one another where they occur together" (Brown and Wilson, 1956 ; p. 63). Hence, they did not make a clear distinction between the selective process, or processes, and the associated spatial pattern. Furthermore, while identifying "ecological [character] displacement," they did not provide a term for what is now generally called "reproductive character displacement." Contrary to Butlin (1989), and to avoid further confusion, we follow Blair (1955a) and apply "reinforcement" to the selective processes that cause the accentuation of differences, and restrict the term "reproductive character displacement" to the pattern of geographic variation in which differences in systems of mate attraction and choice are greater in sympatric populations when compared with those in the allopatric populations. The latter term is thus used purely in a descriptive manner, and without the invoking of any particular evolutionary mechanism to explain the pattern of geographic variation. It seems that there is no comparable term, other than interspecific competition, for the selective processes that may account for ecological character displacement.

Blair (1955b) also found a clinal trend in snout-vent length of sexually mature males and females of $G$. carolinensis and $G$. olivacea, similar to that in call structure, and suggested that the differences in size possibly could act as an isolation mechanism. He noted (Blair, 1955b; p. 301) that: "One of these call characteristics, frequency, probably is directly related to body size, for smaller anurans of any given group tend to have a higher pitched call than larger ones of the same group. The other, length of call, appears unrelated to size." On the basis of these studies by Blair $(1955 a, 1955 b)$, the sympatric divergence in $G$. carolinensis and $G$. olivacea was used as an example of character displacement by Brown and Wilson (1956).

Awbrey (1965) reanalyzed the tape recordings used by Blair (1955a) to extract another attribute, pulse rate. For uncorrected values within a water-temperature range of 24 to $26^{\circ} \mathrm{C}$, he found that, although there was a slight overlap in ranges of variation, there were greater interspecific differences between calls of sympatric (overlap) populations when compared with those of the adjacent allopatric populations (east or west of overlap) (Awbrey, 1965; p. 46 and Fig. 18), thus giving further support to the hypothesis of reinforcement.

Because of the state of technology of magnetic tape recording and acoustic analysis at the time of this classical study by Blair (1955a), these recordings of advertisement calls of Gastrophryne may have been overmodulated and audiospectrograms over- 
TABLE 1. Locations of recording sites and sizes of samples.

\begin{tabular}{|c|c|c|c|c|}
\hline $\begin{array}{l}\text { Sample } \\
\text { number }\end{array}$ & $\begin{array}{l}\text { Number } \\
\text { recorded }\end{array}$ & $\begin{array}{l}\text { Number } \\
\text { collected }\end{array}$ & Species & Locality \\
\hline 1 & 12 & 8 & G. olivacea & 12.9 and $16.1 \mathrm{~km} \mathrm{~N}$ of Kerrville, Texas \\
\hline 2 & 13 & 8 & G. olivacea & $4.8 \mathrm{~km} \mathrm{E}$ of San Diego, Texas \\
\hline$\overline{3}$ & 17 & 14 & $G$. olivacea & $3.2 \mathrm{~km}$ E of Seguin, Texas \\
\hline 4 & 9 & 9 & G. olivacea & $4.8 \mathrm{~km} \mathrm{E}$ of Liberty Hill, Texas \\
\hline 5 & 6 & 4 & G. olivacea & $12.6 \mathrm{~km}$ SE of Gatesville, Texas \\
\hline 6 & 8 & 7 & $G$ olivacea & $16.1 \mathrm{~km} \mathrm{NE}$ of Taylor, Texas \\
\hline 7 & $13^{1}$ & 4 & G. olivacea & 4.8-20.9 km SE of Victoria, Texas \\
\hline 8 & 10 & 0 & G. carolinensis & 16.1 km E of Placedo, Texas \\
\hline 9 & 20 & 15 & $G$. olivacea & $4.8 \mathrm{~km} \mathrm{~N}$ of Trinidad, Texas \\
\hline 10 & 11 & 9 & G. olivacea & $1.6 \mathrm{~km} \mathrm{~S}$ of North Zulch, Texas \\
\hline 11 & 2 & 1 & G. carolinensis & $4.8 \mathrm{~km} \mathrm{~S}$ of Mineola, Texas \\
\hline 12 & 18 & 0 & G. carolinensis & $8.0 \mathrm{~km} \mathrm{NE}$ of Huntsville, Texas \\
\hline 13 & 12 & 9 & G. olivacea & $6.4 \mathrm{~km} \mathrm{NE}$ of Huntsville, Texas \\
\hline 14 & 4 & 0 & G. carolinensis & $24.1 \mathrm{~km} \mathrm{~W}$ of Rusk, Texas \\
\hline 15 & 5 & 1 & G. carolinensis & $16.1 \mathrm{~km} \mathrm{E}$ of Rusk, Texas \\
\hline 16 & 8 & 1 & G. carolinensis & 4.8 and $12.9 \mathrm{~km} \mathrm{~W}$ of Grand Chenier, Louisiana \\
\hline 17 & $26^{1}$ & $17^{1}$ & G. carolinensis & New Orleans (east side), Louisiana \\
\hline
\end{tabular}

I Sample size reduced by 1 for statistical analyses, because of exclusion of outlier. See text for explanation.

loaded, with resultant frequency distortion. Blair (1955a) did not determine the correlation between body length and midpoint frequency for individuals. In addition, the water temperature apparently was not measured at the calling site of each recorded individual, and one temperature from the surface of the pond was used for all recordings obtained during one session at a locality.

Accordingly, it was decided to reinvestigate the patterns of geographic variation in structure of advertisement calls of $G$. carolinensis and $G$. olivacea to (1) minimize the likelihood of overmodulation during recording and spectrographic analysis; (2) compare pulse rates as well as durations and dominant frequencies; (3) measure the surface water temperatures at the calling site of each recorded male so that more precise regressions of call attributes against temperature could be carried out; and (4) collect as many of the recorded males as possible so that the correlations between call attributes and body size could be determined.

\section{Materials AND Methods}

Recordings were made at 17 localities in Texas and Louisiana (Table 1, Fig. 1) during the period 22 April to 1 June 1974. Seven of the 10 samples of recordings of $G$. olivacea are from sites (Fig. 1, localities 1-7) that are close to the presumed western boundary of the zone of sympatry (based on maps presented by Nelson, $1972 b, 1972 c)$. Because of the lack of detailed information about the western limits of continuous distribution of $G$. carolinensis, and the two locality records of this species well to the west of the border as plotted by Nelson $(1972 b)$, it seems conservative to treat these samples as neither allopatric nor sympatric; rather, they have been combined into a category of adjacent allopatry/shallow sympatry. The remaining three samples of $G$. olivacea clearly are from the area of geographic over-

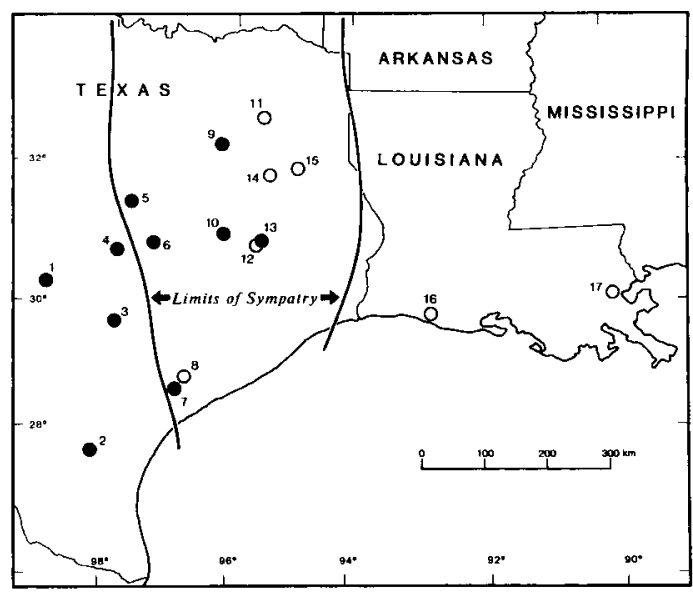

FIG. 1. Map of the south-central United States showing the locations of the recording sites and the approximate area of the southern part of the zone of sympatry between Gastrophryne carolinensis and $G$. olivacea. 
lap, and have been grouped into the central sympatric area (Fig. 1, localities 9, 10, and 13). Two allopatric samples of $G$. carolinensis were obtained in southern Louisiana, about $120 \mathrm{~km}$ and $380 \mathrm{~km}$ from the eastern edge of the zone of sympatry (Fig. 1, localities 16 and 17). The remaining five samples of this species are from sites well within the zone of sympatry (Fig. 1, localities 8, 11, 12,14 , and 15). One of the sympatric samples of $G$. carolinensis (Table 1, locality 12) was obtained at a syntopic site (sensu Rivas, 1964), but the nearest recordings of $G$. olivacea are from $1.0 \mathrm{~km}$ away at locality 13 (Table 1).

An open-reel tape recorder (Nagra IIIB; tape speed $19 \mathrm{~cm} \mathrm{sec}^{-1}$ ) and a dynamic microphone (American Microphone Company Type D33) were used to obtain the recordings, with low noise $40 \mu \mathrm{m}$ polyester magnetic tape (Scotch Dynarange Type 202 or 211 ) as the recording medium. The recording-level indicator of the Nagra IIIB tape recorder (modulometer) has an integration time of $10 \mathrm{~ms}$ (manufacturer's specification), thus reducing the likelihood of overmodulation. Males of the two species of Gastrophryne generally call while floating, and are assumed to be at thermal equilibrium with the adjacent water (see Fouquette, 1980 for a discussion). Accordingly, surface water temperatures were taken at the calling sites of recorded frogs; and, where possible, the specimens were collected after several calls of each individual had been recorded. Those recorded individuals that were collected [20 (27.4\%) of G. carolinensis; $87(72.5 \%)$ of $G$. olivacea] were preserved, and the body lengths (snout-vent) determined to $0.1 \mathrm{~mm}$. Tape recordings, recorded specimens, and field notes are lodged with the Museum of Zoology, University of Michigan.

Descriptions of the advertisement calls of each species, together with audiospectrograms, are presented by Blair (1955a) and Nelson $(1972 b, 1972 c)$. The species are very similar in external morphology, and are usually identified by the extent of pigmentation on the ventral surface $(G$. carolinensis-strongly pigmented and mottled; $G$. olivacea-light and unmarked or virtually so), although confusion may occur where the ranges of the two species overlap (Co- nant and Collins, 1991; p. 332). But it is clear from the discussion by Nelson (1972a; p. 116) that difficulties may be experienced in classifying preserved specimens, and in recognizing hybrids. In our study, taxonomic identification of recorded individuals is based on the structure of the advertisement calls, a most reliable criterion for sympatric species of anurans (Littlejohn, 1969). As indicated by Blair (1955a), there is a large difference in midpoints of emphasized bands of frequencies, with the mean value for $G$. olivacea being $1,333( \pm 58) \mathrm{Hz}$ higher than that for $G$. carolinensis.

Our recordings were analyzed by means of an analogue sound spectrograph (Kay Elemetrics Model 7030A Vibralyzer), with playback on a Nagra IV-L tape recorder (specifications similar to those for the Nagra IIIB tape recorder). Where it was necessary to increase temporal resolution so that pulses could be counted or where the duration of a call exceeded $2.4 \mathrm{sec}$, the tapes were replayed at 9.5 or $38.0 \mathrm{~cm} \mathrm{sec}^{-1}$ respectively. The last clear (i.e., free of overlap with calls of neighbors) and complete call in the recorded sequence of an individual was analyzed ( $300 \mathrm{~Hz}$ filter setting) for determination of call duration (to nearest $5 \mathrm{msec}$ ) and pulse rate (based on the number of pulses over $200 \mathrm{msec}$ near the middle of the call). The frequency of greatest amplitude was considered to be the dominant frequency, and was determined (to the nearest $50 \mathrm{~Hz}$ ) from an audiospectrographic section (FL-1 shape, $45 \mathrm{~Hz}$ filter setting) taken near the middle of the call. If the energy was evenly distributed over two or more peaks (i.e., peaks differed by no more than $3 \mathrm{~dB}$ ), then the mean value was used as the dominant frequency for that call. These peaks of similar amplitude are presumed to be the carrier frequency and adjacent sidebands. See Watkins (1967) for a discussion of this process.

Temporal and spectral calibrations of the Vibralyzer were checked and found to be within the manufacturer's specifications. Variations in tape speed (for recording and playback) are estimated to be less than $\pm 0.5 \%$, and the frequency responses of the microphone and tape recorders are assumed to be close to linear within the range of 2,500 to $5,000 \mathrm{~Hz}$. Statistical analyses were car- 


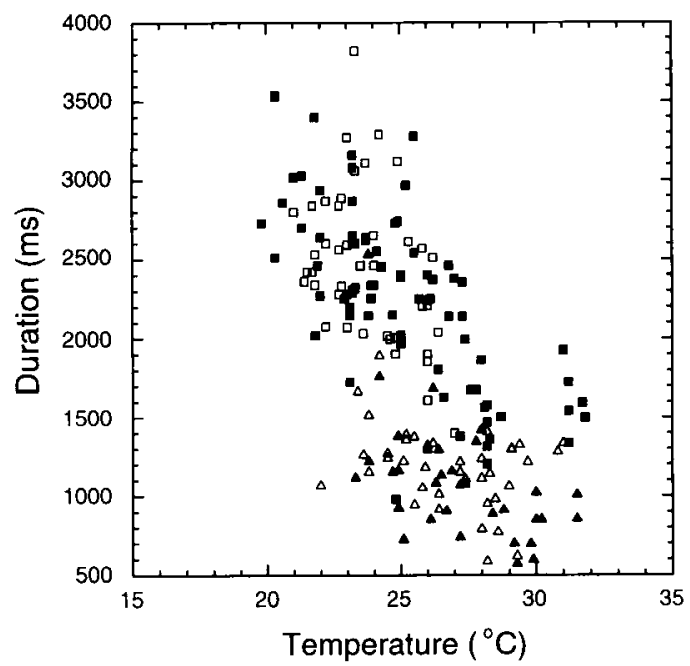

Fig. 2. Scattergram of values for call duration plotted against water temperatures at the calling sites. Key to symbols: Gastrophryne carolinensis - solid triangles $=$ allopatric sites, open triangles = sympatric sites; $G$. olivacea-solid squares = allopatric/adjacent sympatric sites, open squares $=$ sympatric sites.

ried out with SYSTAT, Version 5 (Systat, Inc.).

\section{RESULTS}

As a first step in the analysis, all data for each of the three call attributes (duration, pulse rate, and dominant frequency) were combined into scattergrams for each area sample by plotting each attribute against water temperature as the independent variable (Figs. 2-4). It was at this stage that two outliers for dominant frequency became apparent. The first (dominant frequency $=$ $4,850 \mathrm{~Hz}$, duration $=738 \mathrm{msec}$, pulse rate $=218 \mathrm{p} \mathrm{sec}^{-1}$; water temperature $=27.2^{\circ} \mathrm{C}$ ) is in the sample from locality 17. As this outlier is from the allopatric zone of $G$. carolinensis, it is assumed to be an aberrant individual rather than a hybrid, and was excluded from further calculations. The other call (dominant frequency $=3,600 \mathrm{~Hz}$, duration $=1,080 \mathrm{msec}$, pulse rate $=230 \mathrm{p}$ $\mathrm{sec}^{-1}$, water temperature $=27.4^{\circ} \mathrm{C}$ ) is from an individual recorded at locality 7 within the zone of sympatry, and may be from a hybrid. Accordingly, this call is also excluded from the statistical analyses. Thus, other than these two exceptions, calls of all recorded males could be assigned to either taxon on the basis of dominant frequency

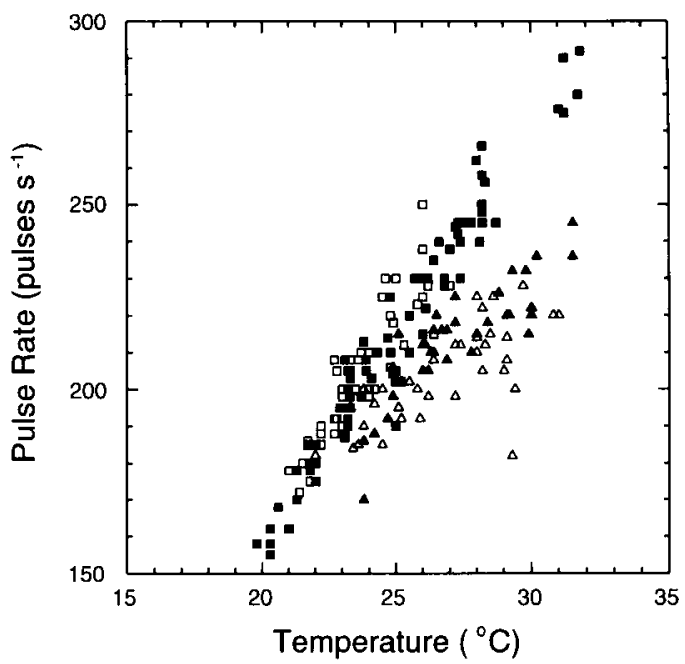

FIG. 3. Scattergram of values for pulse rate plotted against water temperatures at the calling sites. Key to symbols: Gastrophryne carolinensis - solid triangles = allopatric sites, open triangles = sympatric sites; $G$. olivacea-solid squares = allopatric/adjacent sympatric sites, open squares $=$ sympatric sites.

(Blair, 1955a; Awbrey, 1965), namely calls of 72 males of $G$. carolinensis from 7 localities, and of 120 males of $G$. olivacea from 10 localities (Table 1). Water temperatures ranged from 22.0 to $31.5^{\circ} \mathrm{C}($ mean $=27.01)$

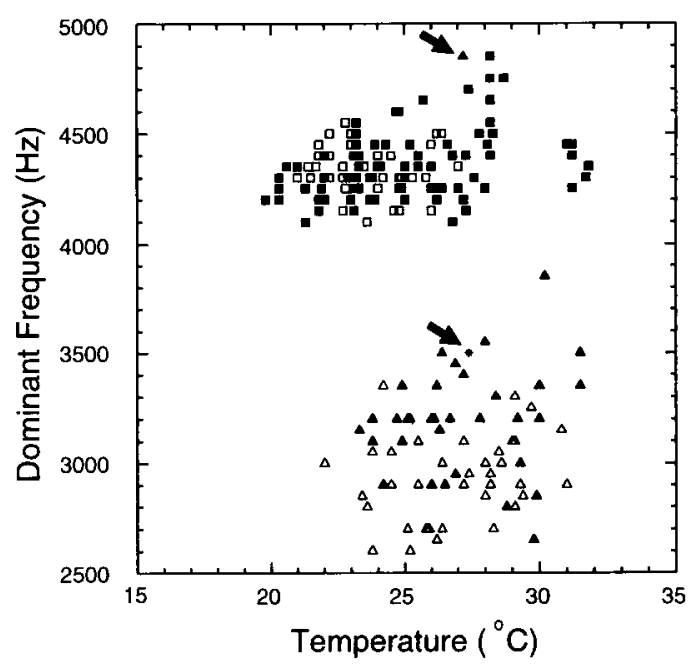

FIG. 4. Scattergram of values for dominant frequency plotted against water temperatures at the calling sites. Key to symbols: Gastrophryne carolinensis-solid triangles = allopatric sites, open triangles = sympatric sites; $G$. olivacea-solid squares = allopatric/ adjacent sympatric sites, open squares = sympatric sites; $*$ = putative hybrid. 
TABLE 2. Results of nested analyses of covariance for three attributes of the advertisement calls of Gastrophryne carolinensis $(N=71)$ and $G$. olivacea $(N=105)$. For each species, temperature is the covariate, and locality is nested within area. See the text for an explanation of the analytical procedure.

\begin{tabular}{|c|c|c|c|c|c|}
\hline Species & Attribute & Area & Locality & Temperature & $\begin{array}{c}\text { Homogeneity of } \\
\text { slopes }\end{array}$ \\
\hline \multirow[t]{3}{*}{ G. carolinensis } & Duration & $\begin{aligned} d f & =1,5 \\
F & =0.707 \\
P & =0.439\end{aligned}$ & $\begin{aligned} d f & =5,63 \\
F & =2.377 \\
P & =0.049\end{aligned}$ & $\begin{aligned} d f & =1,63 \\
F & =5.596 \\
P & =0.021\end{aligned}$ & $\begin{aligned} d f & =5,58 \\
F & =1.192 \\
P & =0.325\end{aligned}$ \\
\hline & Pulse rate & - & - & - & $\begin{aligned} d f & =5,58 \\
F & =4.215 \\
P & =0.002\end{aligned}$ \\
\hline & Dominant freq. & $\begin{aligned} d f & =1,5 \\
F & =20.536 \\
P & =0.006\end{aligned}$ & $\begin{aligned} d f & =5,63 \\
F & =0.657 \\
P & =0.657\end{aligned}$ & $\begin{aligned} d f & =1,63 \\
F & =2.518 \\
P & =0.118\end{aligned}$ & $\begin{aligned} d f & =5,58 \\
F & =1.047 \\
P & =0.399\end{aligned}$ \\
\hline \multirow[t]{3}{*}{ G. olivacea } & Duration & $\begin{aligned} d f & =1,8 \\
F & =0.238 \\
P & =0.639\end{aligned}$ & $\begin{aligned} d f & =8,94 \\
F & =3.823 \\
P & =0.001\end{aligned}$ & $\begin{aligned} d f & =1,94 \\
F & =3.563 \\
P & =0.062\end{aligned}$ & $\begin{aligned} d f & =7,87 \\
F & =1.081 \\
P & =0.382\end{aligned}$ \\
\hline & Pulse rate & $\begin{aligned} d f & =1,8 \\
F & =1.619 \\
P & =0.239\end{aligned}$ & $\begin{aligned} d f & =8,94 \\
F & =6.039 \\
P & =0.000\end{aligned}$ & $\begin{aligned} d f & =1,94 \\
F & =189.146 \\
P & =0.000\end{aligned}$ & $\begin{aligned} d f & =7,87 \\
F & =1.791 \\
P & =0.099\end{aligned}$ \\
\hline & Dominant freq. & $\begin{aligned} d f & =1,8 \\
F & =0.016 \\
P & =0.903\end{aligned}$ & $\begin{aligned} d f & =8,94 \\
F & =2,804 \\
P & =0.008\end{aligned}$ & $\begin{aligned} d f & =1,94 \\
F & =0.550 \\
P & =0.460\end{aligned}$ & $\begin{aligned} d f & =7,87 \\
F & =0.341 \\
P & =0.933\end{aligned}$ \\
\hline
\end{tabular}

for $G$. carolinensis, and from 19.8 to $31.8^{\circ} \mathrm{C}$ (mean $=24.62$ ) for $G$. olivacea.

For each species, the combined samples were then subjected to nested analyses of covariance, with temperature as the covariate, area as the grouping factor, and locality nested within area. For the two area samples of each species, only the data obtained over similar ranges of water temperature (keeping to extreme values that differed by no more than $1.0^{\circ} \mathrm{C}$ ) were considered in the analyses (an assumption of the analysis of covariance). These temperature ranges were reduced to 23.3 to $31.5^{\circ} \mathrm{C}($ mean $=27.08)$ for $G$. carolinensis, and 20.3 to $28.0^{\circ} \mathrm{C}$ (mean $=24.01$ ) for $G$. olivacea. As a consequence, sample sizes for areas were reduced by 15 for $G$. olivacea (locality $2-6$, locality $6-1$, locality $7-8$ ) but only by one (locality 14) for $G$. carolinensis (Table 1). To test for homogeneity of slopes, the models were first run with the interaction terms. They were then run without the interaction terms for all but the one that was significant (pulse rate for G. carolinensis) (Table 2). There are significant effects for localities nested within areas for all attributes of the calls except dominant frequency for $G$. carolinensis $(P$ $=0.657$, Table 2). In this case, the effect of area is highly significant $(P=0.006$, Table 2).
Linear regression analyses of each call attribute for each complete area sample were then carried out, with temperature as the independent variable (Table 3 ). Where the slopes were significant, the data for dominant frequency, the only attribute for which the effect of area is significant (Table 2), were adjusted to $25.0^{\circ} \mathrm{C}$, a temperature that is close to the grand mean for both species $\left(25.52^{\circ} \mathrm{C}\right)$, and the same as that used by Blair $(1955 a)$. The temperature-adjusted data are presented as box plots (McGill et al., 1978) in Figure 5. To display the detailed pattern of geographic variation in dominant frequency for $G$. carolinensis, box plots are presented for each locality (Fig. 6).

To assess the utility of the temporal attributes, duration and pulse rate, as an alternative means of taxonomic diagnosis, the paired uncorrected values for each individual recorded within similar ranges of water temperature for both species (keeping to extreme values that differed by no more than $1.0^{\circ} \mathrm{C}$ ) of 21.0 to $31.8^{\circ} \mathrm{C}$ were plotted (Fig. 7). The slight overlap between species in the distributions of these coordinates is accounted for by three points: one from the allopatric sample of $G$. carolinensis, and one from each of the allopatric/shallow sympatric and deep sympatric samples of $G$. olivacea (Fig. 7). 
TABLE 3. Results of linear regression analyses of three attributes of the advertisement calls of Gastrophryne carolinensis and $G$. olivacea against water temperature at the recording site as the independent variable. For each species, the data have been separated into two geographic areas: allopatry and sympatry for $G$. carolinensis, and allopatry/adjacent sympatry and sympatry for $G$. olivacea. Explanation of abbreviations: $N=$ size of sample; $b=$ regression coefficient; $P=$ significance of slope; $r^{2}=$ coefficient of determination; dom. freq. $=$ dominant frequency.

\begin{tabular}{|c|c|c|c|c|c|c|}
\hline Species & Area & $N$ & Attribute of call &  & $P$ & $r^{2}$ \\
\hline \multirow[t]{2}{*}{ G. carolinensis } & Allopatry & 33 & $\begin{array}{l}\text { Duration } \\
\text { Pulse rate } \\
\text { Dom. freq. }\end{array}$ & $\begin{array}{r}-91.165 \\
5.888 \\
14.485\end{array}$ & $\begin{array}{r}0.001 \\
<0.001 \\
0.451\end{array}$ & $\begin{array}{l}0.306 \\
0.747 \\
0.018\end{array}$ \\
\hline & Sympatry & 39 & $\begin{array}{l}\text { Duration } \\
\text { Pulse rate } \\
\text { Dom. freq. }\end{array}$ & $\begin{array}{r}-35.517 \\
4.201 \\
18.116\end{array}$ & $\begin{array}{r}0.054 \\
<0.001 \\
0.189\end{array}$ & $\begin{array}{l}0.097 \\
0.526 \\
0.046\end{array}$ \\
\hline \multirow[t]{2}{*}{ G. olivacea } & $\begin{array}{l}\text { Allopatry/ } \\
\text { adjacent } \\
\text { sympatry }\end{array}$ & 77 & $\begin{array}{l}\text { Duration } \\
\text { Pulse rate } \\
\text { Dom. freq. }\end{array}$ & $\begin{array}{c}-140.379 \\
10.97 \\
19.050\end{array}$ & $\begin{array}{r}<0.001 \\
<0.001 \\
0.001\end{array}$ & $\begin{array}{l}0.516 \\
0.953 \\
0.130\end{array}$ \\
\hline & Sympatry & 43 & $\begin{array}{l}\text { Duration } \\
\text { Pulse rate } \\
\text { Dom. freq. }\end{array}$ & $\begin{array}{r}-123.996 \\
10.488 \\
-5.499\end{array}$ & $\begin{array}{r}0.005 \\
<0.001 \\
0.592\end{array}$ & $\begin{array}{l}0.175 \\
0.814 \\
0.007\end{array}$ \\
\hline
\end{tabular}

Twenty males of $G$. carolinensis (one of which was subsequently discarded because of the exceptional dominant frequency - see above) and 87 of $G$. olivacea were collected after their calls had been recorded, and their

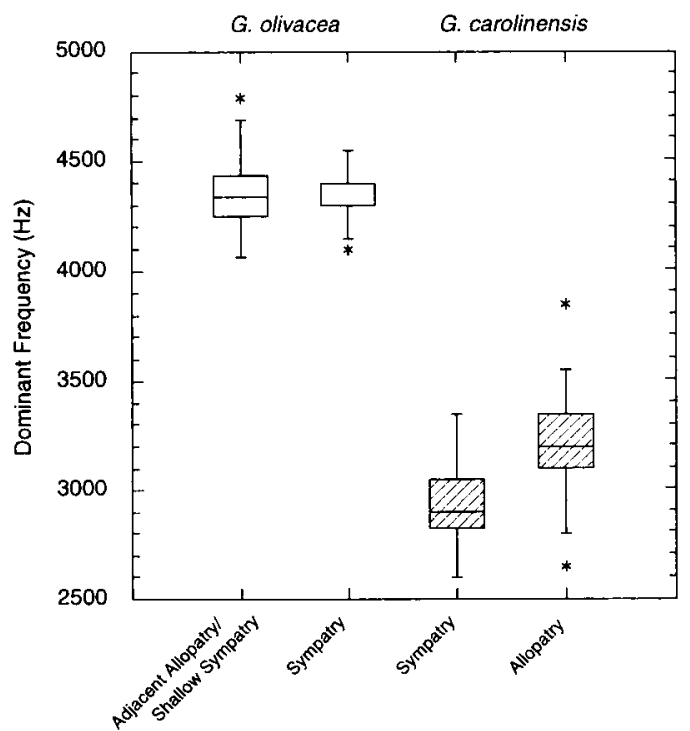

FIG. 5. Box plots of values for dominant frequency of advertisement calls of Gastrophryne carolinensis and $G$. olivacea, adjusted where appropriate (Table 3 ) to a water temperature of $25.0^{\circ} \mathrm{C}$, for the four area samples. Five values are presented: the upper and lower extremes (whiskers-vertical lines), the upper and lower quartiles (hinges - the ends of each box), and the median (horizontal line inside the box); outliers are indicated by asterisks. See McGill et al. (1978) for more information. snout-vent lengths were obtained (Table 4). Samples sizes were large enough to allow separate treatments of the two area samples of $G$. olivacea. There were, however, only sufficient data $(N=17)$ to allow analysis of the allopatric populations of $G$. carolinensis (only two of the recorded sympatric individuals were collected) (Table 1). As the means for the two area samples of $G$. olivacea do not differ significantly $(t=0.771$,

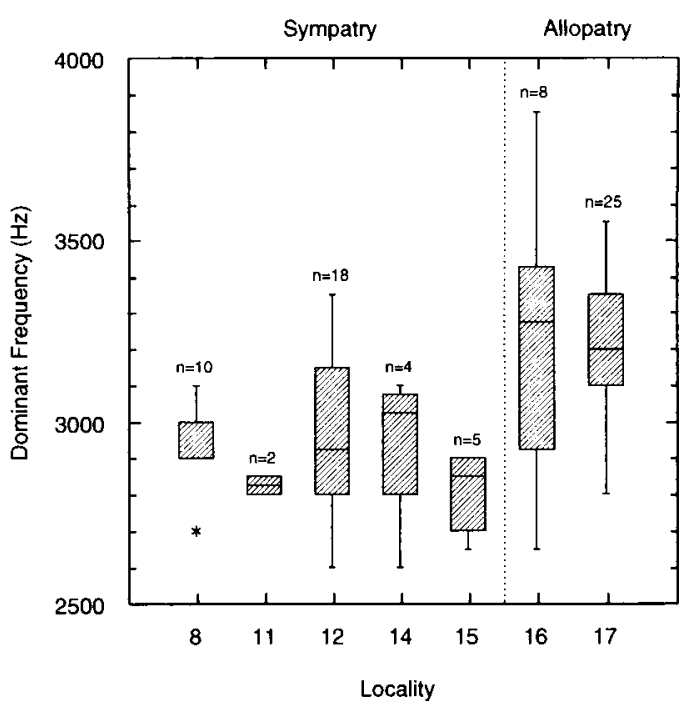

FIG. 6. Box plots of values for dominant frequency of advertisement calls of Gastrophryne carolinensis for all locality samples. See Figure 5 for an explanation of the box plots. Sizes of samples are indicated above each box. 


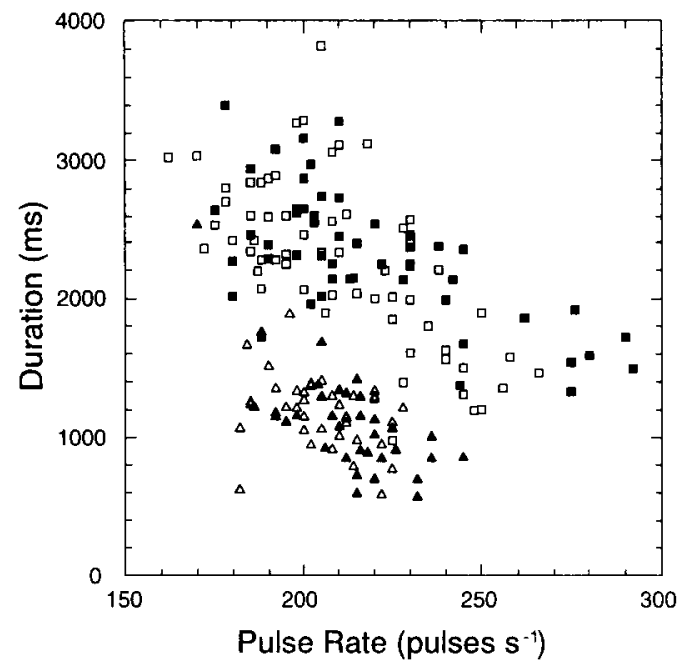

FIG. 7. Scattergram of points for paired values for duration and pulse rate. Key to symbols: Gastrophryne carolinensis $(N=72)$-solid triangles = allopatric sites, open triangles = sympatric sites; $G$. olivacea $(N=115)-$ solid squares $=$ allopatric/adjacent sympatric sites, open squares $=$ sympatric sites.

$P=0.443, d f=85)$, the samples were pooled (mean $=26.20 \mathrm{~mm}$, standard deviation $=$ 1.72). The combined mean for $G$. olivacea was then compared with the mean for the allopatric sample of $G$. carolinensis (mean $=28.55$, Table 4), and found to be highly significantly different $(t=4.993, P<0.001$, $d f=102$ ). Multiple linear regression analyses were carried out, with temperature and body length as the independent variables, and the three attributes of the call as the dependent variables. To determine the strength of the associations, partial correlation coefficients, with the effects of temperature held constant, were then calculated. Significant associations between body length and a call attribute were found for pulse rate $\left(r^{2}=0.588\right)$ in the allopatric population of $G$. carolinensis, and for all three attributes (duration: $r^{2}=0.276$; pulse rate: $r^{2}=0.096$; dominant frequency: $r^{2}=0.102$ ) in the combined allopatric/adjacent sympatric sample of $G$. olivacea (Table 5).

\section{DisCUSSION}

With the exception of the two individuals considered in the Results, the ranges of variation in the values for dominant frequency of each species do not overlap; rather, they are separated by a considerable gap (Fig. 4). This separation, which holds at all recording temperatures and for both allopatric and sympatric samples, is in contrast to the overlapping distributions of the samples from overlap, and east and west of overlap, depicted by Blair (1955a; Fig. 3-about 200 $\mathrm{Hz}$; Fig. 4-about $900 \mathrm{~Hz}$ ). Although the ranges of variation of each of the two temporal attributes, duration and pulse rate, when separately plotted against water temperature, overlap extensively between species (Figs. 2 and 3), there is very little overlap of the scatters of points for the combined values (Fig. 7). This separation may thus provide an additional acoustic character for the identification of parental and hybrid males. For each species, however, the scatter of points for each area sample are very similar, and, in contrast to the findings of Awbrey (1965), do not provide further evidence of reproductive character displacement.

The results of the nested analysis of covariance (Table 2) indicate that there is divergent character displacement in dominant frequency in $G$. carolinensis. The displacement in dominant frequency is most striking, and is unexpected, given that there is no overlap between species of values in either sympatric or allopatric samples of the two species (Figs. 4 and 5). In contrast, Blair (1955a) found displacement of dominant frequency only in G. olivacea. But this ear-

TABLE 4. Sample sizes ( $N$, means, standard deviations (SD), and ranges of snout-vent lengths (mm) of males of Gastrophryne carolinensis and $G$. olivacea, collected after their advertisement calls had been recorded.

\begin{tabular}{clrccc}
\hline \hline Species & \multicolumn{1}{c}{ Area } & $N$ & Mean & SD & Range \\
\hline \multirow{2}{*}{ G. carolinensis } & Allopatry & 17 & 28.55 & 2.08 & $24.9-32.0$ \\
& Sympatry & 2 & 33.00 & - & $32.6-33.4$ \\
G. olivacea & Allopatry/adjacent & 54 & 26.31 & 1.88 & $23.0-30.8$ \\
& sympatry & 33 & 26.02 & 1.41 & $23.4-29.7$ \\
\hline
\end{tabular}


lier comparison was based on the assumption of a much narrower zone of sympatry. Given that the area of overlap of geographic ranges is much greater than that considered by Blair (1955a) (Fig. 1), his samples from east and west of overlap are probably sympatric, and his results may not be inconsistent with the present findings. The box plots for dominant frequency in the separate locality samples of calls of $G$. carolinensis (Fig. 6) suggest that there is a stepped, rather than smooth, cline between allopatry and sympatry. Such an indication is consistent with the explanation based on reinforcement in the calls of $G$. carolinensis as a consequence of an acoustic interaction with the advertisement calls of $G$. olivacea. Gerhardt (1988) has reviewed the significance of spectral components of advertisement calls in mate choice in anurans.

Awbrey (1965) carried out a series of discrimination tests in the laboratory, using repeated tape-recorded natural advertisement calls from sympatric localities, and replayed through loudspeakers, as the stimuli. He used one call from each of three individuals of $G$. olivacea (our designation, A: duration $=3.2 \mathrm{sec}$, pulse rate $=156 \mathrm{p}$ $\mathrm{sec}^{-1}$, dominant frequency $=3,800 \mathrm{~Hz} ; \mathrm{B}$ : $2.2 \mathrm{sec}, 188 \mathrm{p} \mathrm{sec}^{-1}, 4,000 \mathrm{~Hz}$; C: $2.9 \mathrm{sec}$, $235 \mathrm{p} \mathrm{sec}^{-1}, 4,400 \mathrm{~Hz}$ ), one individual of $G$. carolinensis $\left(1.8 \mathrm{sec}, 150 \mathrm{p} \mathrm{sec}^{-1}, 2,800 \mathrm{~Hz}\right)$, and one putative hybrid (1.8 sec, $196 \mathrm{p} \mathrm{sec}^{-1}$, $3,500 \mathrm{~Hz}$ ). Reproductively ripe females of $G$. olivacea, from several localities within the broader zone of sympatry as now recognized, were the subjects. His experiments were complicated by the repeated testing of females, and by use of the calls of three males of $G$. olivacea that differed in duration, pulse rate and dominant frequency, so that the significance of the latter attribute in interspecific discrimination cannot be determined. Even so, his results indicate effective call discrimination and positive phonotaxis to the conspecific call by sympatric females of $G$. olivacea. The phonotactic responses by females when the hybrid call and each of the three conspecific calls were used as the stimuli (in separate experiments) suggest that discrimination may be possible only when there is sufficient difference in dominant frequency (i.e., $900 \mathrm{~Hz}$, rather than 300 to $500 \mathrm{~Hz}$ ). The temporal differentiation (resulting from the combination of duration and pulse rate) (Fig. 7) may complement the spectral differences in dominant frequency in enabling selective phonotaxis by breeding females. Clearly, further research into phonotaxis and discrimination should be carried out, given the results of these interesting preliminary studies.

Our failure to detect any significant hybridization [only one possible case in a minimum of 83 definitely sympatric individuals (1.2\%), whereas Blair (1955a) reported eight assumed hybrids $(8.0 \%)$ in a sample of 100 individuals recorded in sympatry] is of interest. No explanation for the difference in results can be given at present. Even where genetic compatibility is present, and fertile hybrids survive to maturity under laboratory conditions, the intermediacy of ecological adaptation could lead to the premature elimination of the hybrids in natural systems through competitive interactions with parental individuals (Littlejohn, 1981). Divergence in dominant frequencies could also result solely from the enhancement of efficiency of acoustic communication (Littlejohn, 1977, 1988), especially where the auditory pathways of the receivers are broadly tuned (Narins and Zelick, 1988).

Volpe (1957) questioned the interpretations of Blair $(1955 a, 1955 b)$ of reinforcement as the selective mechanism on two bases: (1) "Critical evidence is lacking that the hybrids are less viable, less fertile, or less well adapted than the parental types. Moreover, the frequency of hybridization may be so low as to preclude the operation of selection" (p. 366); and (2) "A simpler and more plausible interpretation is that the clines demonstrated by W. F. Blair are due to local differences in selection in the range of each species, possibly correlated with environmental gradients. ... The two species, differing in their habitat requirements, most likely compete with each other for suitable ecological niches. If differences in body size and mating call, by themselves or associated with other characters, tend to reduce competition between the two species, then selection acting on the total population may augment the differences" (p. 367). Hence, the clines could have resulted from selective processes other than direct interspecific in- 
TABLE 5. Values for probability $(P)$ of the significance of slopes resulting from multiple linear regression analyses of three attributes of the advertisement calls of Gastrophryne carolinensis and $G$. olivacea against the variables, water temperature at the calling site and the snout-vent length of the emitter. Partial correlation coefficients ( $r$ ) for the association of call attribute and snout-vent (s-v) length when the effect of temperature is held constant are also presented. $N=$ size of sample; dom. freq. = dominant frequency.

\begin{tabular}{|c|c|c|c|c|c|c|}
\hline Species & Area & $N$ & Attribute of call & $\begin{array}{c}\text { Temperature } \\
(P)\end{array}$ & $\begin{array}{l}\text { Length (s-v) } \\
(P)\end{array}$ & $\begin{array}{l}\text { Partial correl. } \\
\text { coeff. }(r)\end{array}$ \\
\hline G. carolinensis & Allopatry & 17 & $\begin{array}{l}\text { Duration } \\
\text { Pulse rate } \\
\text { Dom. freq. }\end{array}$ & $\begin{array}{r}0.026 \\
<0.001 \\
0.293\end{array}$ & $\begin{array}{l}0.056 \\
0.001 \\
0.194\end{array}$ & $\begin{array}{r}0.486 \\
-0.767 \\
-0.343\end{array}$ \\
\hline \multirow[t]{2}{*}{ G. olivacea } & $\begin{array}{l}\text { Allopatry/adjacent } \\
\text { sympatry }\end{array}$ & 54 & $\begin{array}{l}\text { Duration } \\
\text { Pulse rate } \\
\text { Dom. freq. }\end{array}$ & $\begin{array}{r}<0.001 \\
<0.001 \\
0.014\end{array}$ & $\begin{array}{r}<0.001 \\
0.024 \\
0.019\end{array}$ & $\begin{array}{r}0.525 \\
-0.310 \\
-0.320\end{array}$ \\
\hline & Sympatry & 33 & $\begin{array}{l}\text { Duration } \\
\text { Pulse rate } \\
\text { Dom. freq. }\end{array}$ & $\begin{array}{r}0.013 \\
<0.001 \\
0.386\end{array}$ & $\begin{array}{l}0.384 \\
0.107 \\
0.395\end{array}$ & $\begin{array}{r}0.159 \\
-0.291 \\
0.156\end{array}$ \\
\hline
\end{tabular}

teractions involving choice of mates, and were perhaps incidental, pleiotropic effects.

We found no consistent pattern of correlation between body size, as reflected in snout-vent length, and the three attributes of the advertisement call (Table 5). Thus, our results do not support the suggestion of Volpe (1957) that indirect (pleiotropic) effects of changes in body size and proportions in response to environmental gradients, rather than reinforcement, may provide an adequate explanation for the geographic variation in dominant frequency. More information is required, however, on other morphological measurements, such as head width and volume of the vocal sac, before any firm conclusions can be reached. While differences in terrestrial vegetation could be of importance as an environmental factor affecting the evolution of long-range acoustic signals (Nevo and Capranica, 1985; Ryan, 1988), the significance of differences in the adjacent emergent aquatic vegetation in the close-range acoustic environments of species that call and mate while floating has yet to be determined.

This interaction between $G$. carolinensis and $G$. olivacea remains one of great significance, both historically and in the present context of dispute over the significance of reproductive character displacement and reinforcement in speciation (Butlin, 1987, 1989; Paterson, 1985). The situation clearly warrants further precise, detailed and geographically extensive studies, particularly (1) detailed and accurate mapping of the geographic distributions of the two species, together with an assessment of the extent of synchronous syntopy, to determine the extent and limits of sympatry; (2) procurement of samples of recordings of advertisement calls from remote and contiguous allopatric populations of each species; (3) comprehensive analyses of correlations between structure of the calls and morphological attributes of the emitters; (4) determination of the characteristics of the auditory pathway of females, particularly frequency resolution; (5) description of vegetation at calling sites and other aspects of the acoustic environment, and assessment of possible effects of these environmental components on the evolution of acoustic signals; (6) comparative studies of reproductive behavior, including chorus structure and territorial interactions in syntopy, allotopy, and allopatry, and the phonotactic behavior of breeding females; and (7) determination of the occurrence, viability and fertility of hybrids.

\section{ACKNOWLEDGMENTS}

The costs of the field program and provision of the salary for J.J.L-H., and the air fares between Melbourne and Ann Arbor for M.J.L., were met from NSF Grant GB 40068 to R. D. Alexander. Other support was provided by the Museum of Zoology, University of Michigan. Special research leave for one month was granted by the University of Melbourne to allow M.J.L. to travel to Ann Arbor to carry out the acoustic analysis of the tape recordings obtained by J.J.L-H. Subsequent statistical treatment of the data and preparation of the manuscript 
were carried out in the Department of Zoology, University of Melbourne. This manuscript was completed during the tenure of a grant from the Australian Research Council (ARC Grant No. A18831316 to M.J.L.). P. A. Harrison prepared the data for computer processing. J. R. Wright assisted with the statistical analyses and preparation of the associated figures. M. J. Keough, G. P. Quinn, and P. T. Raimondi gave advice on statistical analyses and application of the software package. H. C. Gerhardt and G. F. Watson provided valuable comments on the manuscript.

\section{Literature CITED}

AWBreY, F. T. 1965. An experimental investigation of the effectiveness of anuran mating calls as isolating mechanisms. Ph.D. Diss. University of Texas, Austin, USA.

BLAIR, W. F. 1955a. Mating call and stage of speciation in the Microhyla olivacea-M. carolinensis complex. Evolution 9:469-480.

- $1955 b$. Size difference as a possible isolation mechanism in Microhyla. Am. Nat. 89:297-301.

Brown, W. L., AND E. O. WILSON. 1956. Character displacement. Syst. Zool. 5:49-64.

Butlin, R. 1987. Speciation by reinforcement. Tr. Ecol. Evol. 2:8-13.

- 1989. Reinforcement of premating isolation, pp. 158-179. In D. Otte and J. A. Endler (eds.), Speciation and Its Consequences. Sinauer Associations, Inc., Sunderland, MA USA.

Conant, R., AND J. T. Collins. 1991. A Field Guide to Reptiles and Amphibians. Eastern and Central North America, 3rd ed. Houghton Mifflin Co., Boston, MA USA.

FouquetTe, M. J. 1980. Effect of environmental temperatures on body temperature of aquatic-calling anurans. J. Herpetol. 14:347-352.

GerhardT, H. C. 1988. Acoustic properties used in call recognition by frogs and toads, pp. 455-483. In B. Fritzsch, M. J. Ryan, W. Wilczynski, T. E. Hetherington, and W. Walkowiak (eds.), The Evolution of the Amphibian Auditory System. John Wiley and Sons, N.Y., USA.

Littlejohn, M. J. 1969. The systematic significance of isolating mechanisms, pp. 459-482. In Systematic Biology. Proceedings of an International Conference. National Academy of Sciences, Wash., DC USA.

-. 1977. Long-range acoustic communication in anurans: An integrated and evolutionary ap- proach, pp. 263-294. In D. H. Taylor and S. I. Guttman (eds.), The Reproductive Biology of Amphibians. Plenum Press, N.Y., USA.

1981. Reproductive isolation: A critical review, pp. 298-334. In W. R. Atchley and D. S. Woodruff (eds.), Evolution and Speciation. Essays in Honor of M. J. D. White. Cambridge University Press, Cambridge, UK.

- 1988. Frog calls and speciation. The retrograde evolution of homogamic acoustic signaling systems in hybrid zones, pp. 613-635. In B. Fritzsch, M. J. Ryan, W. Wilczynski, T. E. Hetherington, and W. Walkowiak (eds.), The Evolution of the Amphibian Auditory System. John Wiley and Sons, N.Y., USA.

McGill, R., J. W. Tukey, AND W. A. LARSEN. 1978. Variations of box plots. Am. Stat. 32:12-16.

NARINS, P. M., AND R. Zelick. 1988. The effects of noise on auditory processing and behavior in amphibians, pp. 51 1-536. In B. Fritzsch, M. J. Ryan, W. Wilczynski, T. E. Hetherington, and W. Walkowiak (eds.), The Evolution of the Amphibian Auditory System. John Wiley and Sons, N.Y., USA.

Nelson, C. E. 1972a. Systematic studies of the North American microhylid genus Gastrophryne. J. Herpetol. 6:111-137.

1972b. Gastrophryne carolinensis (Holbrook). Cat. Am. Amphib. Rept. 120:1-4.

-1972c. Gastrophryne olivacea (Hallowell). Cat. Am. Amphib. Rept. 122:1-4.

Nevo, E., AND R. R. CaPranica. 1985. Evolutionary origin of ethological reproductive isolation in cricket frogs. Evol. Biol. 10:147-214.

Paterson, H. E. H. 1985. The recognition concept of species, pp. 21-29. In E. S. Vbra (ed.), Species and Speciation. Transvaal Museum, Pretoria, South Africa.

Rivas, L. R. 1964. A reinterpretation of the concepts "sympatric" and "allopatric" with proposal of the additional terms "syntopic" and "allotopic." Syst. Zool. 13:42-43.

Ryan, M. J. 1988. Constraints and patterns in the evolution of anuran acoustic communication, pp. 637-677. In B. Fritzsch, M. J. Ryan, W. Wilczynski, T. E. Hetherington, and W. Walkowiak (eds.), The Evolution of the Amphibian Auditory System. John Wiley and Sons, N.Y., USA.

VOLPE, E. P. 1957. Genetic aspects of anuran populations. Am. Nat. 91:355-371.

WATKINS, W. A. 1967. The harmonic interval: Fact or artifact in spectral analysis of pulse trains, pp. 15-43. In W. N. Tavolga (ed.), Marine Bio-Acoustics, Vol. 2. Pergamon Press, Oxford, UK.

Corresponding Editor: T. Markow 